Canadian

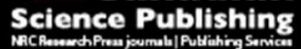

Canadian Journal of Forest Research Revue canadienne de recherche forestière

\title{
VIABILITY AND GERMINATION OF SCOTS PINE SEEDS AFTER FREEZING OF HARVESTED CONES IN VITRO
}

\begin{tabular}{|r|l|}
\hline Journal: & Canadian Journal of Forest Research \\
\hline Manuscript ID & cjfr-2016-0107.R1 \\
\hline Manuscript Type: & Article \\
\hline Date Submitted by the Author: & $26-$ May-2016 \\
\hline Complete List of Authors: & $\begin{array}{l}\text { Nygren, Markku; Natural Resources Institute Finland, } \\
\text { Himanen, Katri; Natural Resources Institute Finland, } \\
\text { Ruhanen, Hanna; Natural Resources Institute Finland, Suonenjoki }\end{array}$ \\
\hline Keyword: & freezing, maturation, x-ray, cone, storage \\
\hline
\end{tabular}

SCHOLARONE ${ }^{\text {IM }}$

Manuscripts 
1 Markku Nygren ${ }^{\text {a, }}$, Katri Himanen ${ }^{\text {a }}$, Hanna Ruhanen ${ }^{\text {a }}$

2

3

4

5

6

7 VIABILITY AND GERMINATION OF SCOTS PINE SEEDS AFTER FREEZING OF

8 HARVESTED CONES IN VITRO

9

10

$11{ }^{a}$ Natural Resources Institute Finland, Suonenjoki Unit, Juntintie 154, FI-77600 Suonenjoki,

12 Finland

13 markku.nygren@1uke.fi, katri.himanen@1uke.fi, hanna.ruhanen@1uke.fi

$17 *$ Corresponding author

18 e-mail: markku.nygren@1uke.fi

19 tel: +358295324817

20 
21 ABSTRACT

22 Scots pine (Pinus silvestris L.) cone and seed water content were analyzed in two consecutive seasons during maturation stage in the autumn and in January and March before seed dispersal. Cones with different water contents were subjected to $2 \mathrm{~h}$ freezing at $-30{ }^{\circ} \mathrm{C}$ and seed viability and laboratory germination of seeds from individual cones after treatment were analyzed. Seed water content could be well predicted with cone water content measurement and the general relationship between these two could be described with a generalized logistic

28 function. On average, cones had $5-10 \%$ higher water content than the seeds inside them.

29 The higher the cone water content at the onset of freezing treatment, the higher was the

30 proportion of seeds with apparent damage (based on visual inspection of seeds using x-ray

31 images) in that particular cone. High water content in cones also resulted in decreased

32 germination after freezing treatment. The critical cone water content for $50 \%$ germination

33 after freezing at $-30{ }^{\circ} \mathrm{C}$ was approximately $31.3 \%$ (fresh weight basis). This corresponds to

$34 \quad 21.6 \%$ water content in seeds.

35 Keywords: freezing, maturation, cone moisture, $\mathrm{x}$-ray, cone storage 
1. INTRODUCTION

38 Scots pine (Pinus sylvestris L.) is characterized a three-year reproductive cycle typical to many other pine species (Owens and Blake 1985). In the first year, reproductive buds are initiated and formed. Pollination takes place in early summer of the second year. After pollination, pollen tube and ovule development is initiated, but it stops, usually in midsummer. The development resumes the following spring and, after syngamy, a period of seed growth and development follows. Seeds mature in the fall of the third growing season after flower-bud initiation. In boreal zone of Fennoscandia, this phase occurs in late September-

October, approximately 17 months after pollination and four months after syngamy (Sarvas 1962). When mature, cones remain intact on trees over winter and seeds are released next spring, typically in May - June.

Anatomically mature Scots pine seeds have fully developed embryo and megagametophyte tissues. In conifers, this stage is generally used as an indicator of when cones can be picked and successfully after-ripened (Edwards 1980). Based on Simak's (1980) embryo and megagametophyte classification analysis of these tissues has become a routine analysis to estimate the germination potential of conifer seeds in forest tree seed centers in Northern

\section{Europe.}

Besides anatomical maturation, conifer seeds exhibit biochemical (Kardell et al. 1973) and physiological (Edwards 1980) maturation. These are general terms referring to biochemical and physiological changes in both the embryo and megagametophyte during late stages of maturation and include the change from mobile to storage forms of reserves, seed dehydration and decline in respiratory activity. Physiological and biochemical activity in 
61 Scots pine seeds continues after the accumulation of reserves is complete and the embryo is

62 fully elongated. Håkansson (1956), for example, found mitotic activity and formation of starch in Scots pine embryos in late October in seed samples collected in southern Sweden. In this case, the seeds were anatomically fully developed in the middle of August. Recently, Tillman-Sutela \& Kauppi (2014) have shown that maturation of Scots pine seed surface structures - nucellar and megaspore membranes and the three - layer seed coat - play an important role in the maturation process as a whole. The physiological maturation of the above - named structures appears to take place independently of the anatomical development of the embryo and megagametophyte, continuing several weeks after the embryo has reached its final size.

Fundamental to physiological changes in life cycle of orthodox seeds is their dehydration at the final stage of development (Kermode et al. 1986). In a dry state, seeds can tolerate a number of diverse environmental conditions, including extremes in temperature. For Scots pine in Fennoscandia, where temperatures below $-30{ }^{\circ} \mathrm{C}$ are common during winter months, this is critical as seeds must simultaneously mature and become freeze tolerance in order to survive harsh winter conditions.

During seed ripening and the overwintering phase, Scots pine seed development can be disturbed or interrupted by negative temperatures, leading to seed damage and low germinability. Simak (1972) found that the early stages of embryogenesis were more sensitive to cold treatment than were the later ones. In material collected from northern

83 Sweden, Kardell (1974) demonstrated that in natural environments the proportion of Scots

84 pine seed with damaged embryos - as determined with a tetrazolium test - increased from

85 zero in September to 53\% at maximum in February. In a later study, however, he found that 
during the period from the beginning of September to the middle of October, freezing of collected cones at temperatures of $-5{ }^{\circ} \mathrm{C},-10{ }^{\circ} \mathrm{C}$ and $-15{ }^{\circ} \mathrm{C}$ for two, four and eight hours resulted in an increased germination rate. In the following year, the same combinations of time and temperature caused both embryo damage and decreased germination (Kardell, 1976).

Many studies report large annual variation in moisture content of Scots pine cones and seeds during the late stages of maturation at the onset of winter (Sahlen \& Abbing 1995, TillmanSutela \& Kauppi 2014). Nygren \& Pulkkinen (1994) for example, noticed that in northern and southern Scots pine clones growing in a common garden in southern Finland, seed water content varied from approximately 40 to 20 percent (fresh weight basis) at the end of the maturation phase, depending on year and clone, respectively. Thus it may be hypothesized that, depending on the environmental conditions prevailing during maturation, cone and seed dehydration could be incomplete, resulting in seed damage during winter months.

With contradictory results on the role of sub-zero temperatures on Scots pine seed maturation, optimizing the timing of cone collections is problematic. In Fennoscandia, it is often a necessity to start the collections as early as possible before the harsh winter conditions and snow make the operations difficult and more costly. Planning collection timing is further complicated by the fact that clonal sequence and approximate dates of ripening vary (Bonner 1991). Starting collections too early usually results in low germination and short storage life of seeds, while postponing the collection to early winter will increase the risk of frost damage. These risks can be avoided by timely collection and proper post-collection handling of cones and seeds, ie. cone storage and possible artificial ripening of the seeds (Edwards 1980, Sahlen \& Abbing 1995). Nevertheless, when increasing amounts of genetically improved Scots pine seed is used in nurseries and regeneration areas, it is of utmost 
111 importance to optimize the collection timing, so that valuable seed is not lost due to improper 112 timing of collections.

113

114 The objectives of the current study were to evaluate if cone water content could be used to

115 predict the water content of the seeds inside them. A further objective included testing cold

116 hardiness of harvested Scots pine seeds while still in cones, to determine how their

117 subsequent germination and possible freezing injury are affected by cone water content.

118 
119 2. MATERIAL AND METHODS

120

121

\section{Cone collections} 2012.

\section{Cone and seed water content} cones.
Open-pollinated Scots pine cones were collected from Suhola seed orchard no. $404\left(62^{\circ} 15^{\prime} \mathrm{N}\right.$, $27^{\circ} 42^{\prime} \mathrm{E}, 88 \mathrm{~m}$ a.s.1.) in southern Finland. This 1.5 generation orchard was established in 1997, with an area of 26.2 ha and with 35 clones. The number of grafts per clone varies from 104 to 208. Seeds collected represented two crops, maturing in two consecutive growing seasons in 2011 and 2012. Collections for the first crop were done on Nov $21^{\text {st }}, 2011$, Feb $30^{\text {th }} 2012$ and March $26^{\text {th }} 2012$. The seed collection date for the second crop was Nov $5^{\text {th }}$,

In the first season, in November 2011, cones were collected from three clones (E1881, K689 and K393) and from three grafts per clone. The clones and individual grafts were randomly chosen at the beginning of the study, and were used in every collection. During November 2012 collection, one more clone (K942), also with three grafts, was included in the study. From each graft, 25 - 30 cones were picked on each occasion throughout the crown, and transported in sealed, separate plastic bags in an insulated box to the seed laboratory at the Finnish Forest Research Institute (now Natural Resources Institute Finland) in Suonenjoki (approximately a one - hour drive from the seed orchard).

In the laboratory, 3-5 cones from each graft were randomly chosen for the analysis of cone and seed water content. For every collection, each clone was thus represented by $9-15$ 
142 Each cone was cut in four quarters (lengthwise). One of these was used for cone water 143 content measurement by weighing it fresh and after drying at $+103{ }^{\circ} \mathrm{C}$ for $17 \pm 1$ hours. From 144 the other three quarters, a bulk sample of $15-20$ seeds was picked manually, and the sample 145 water content was measured gravimetrically on a fresh weight basis using the constant 146 temperature oven method $\left(103^{\circ} \mathrm{C}, 17 \pm 1 \mathrm{~h}\right)$ (International Rules...2005). Cones damaged by 147 pine cone weevil, Pissodes validirostris Gyll., were excluded from the study.

149 Cone freezing treatment and seed extraction

150 Further, in each collection, 24 cones per clone, 8 from each graft were randomly divided into 151 control and freezing treatment groups, both including 12 cones per clone. Cones from 152 different clones and grafts were kept separate, so that individual cone water content at the onset of freezing could be measured (except first collection, see below). Cones were treated

154 as follows: (1) freezing treatment: starting at $+5{ }^{\circ} \mathrm{C}$ and temperature lowered at a rate of $5{ }^{\circ} \mathrm{C}$ $155 \mathrm{~h}^{-1}$ until $-30{ }^{\circ} \mathrm{C}$ was reached. After $2 \mathrm{~h}$ at $-30{ }^{\circ} \mathrm{C}$, temperature was raised again up to $+5{ }^{\circ} \mathrm{C}$ at 156 a similar rate. The freezing treatment as a whole took 16 hours to complete and was done 157 using a controlled freezing cabinet (Weiss WT-600/70). In the control treatment, the cones 158 were stored in a cold room at $+5{ }^{\circ} \mathrm{C}$ for the same amount of time. The cones were not 159 exposed to light during the treatments.

160 The first collection in Nov 2011 was a pilot study in which seeds extracted from a group of

161 four cones from each clone-graft-treatment combination were treated as a combined sample.

162 Thus, no data on individual cone water content at the onset of the freezing treatment was 163 collected. 
164 In later collections, individual cones were kept separate during the treatment. Similarily, 165 seeds extracted from them were also analyzed cone-wise. Number of filled seeds per cone 166 varied from 11 to 49 . As each clone was represented by four cones from each of three grafts, 167 the total number of seeds from each clone in the germination tests in different collections 168 varied from 330 to 518 . Individual cone water content (fresh weight basis) at the onset of 169 freezing was measured gravimetrically by weighing cones (accuracy $0.01 \mathrm{~g}$ ) before the 170 freezing treatment. After seed extraction $\left(+38^{\circ} \mathrm{C}\right.$, ventilated oven, $\left.48 \mathrm{~h}\right)$ cones were further 171 dried at $+103{ }^{\circ} \mathrm{C}$ to a constant weight.

172 Seed wings were removed manually and seeds were stored in airtight pouches at $+5{ }^{\circ} \mathrm{C}$ 173 (typically $2-3$ weeks) before germination tests.

Germination and seed $x$-raying

176 Seeds were germinated, cone-wise in a $90 \mathrm{~mm}$ Petri dish, each with two layers of germination 177 paper (Munktell 1701) moistened with $5 \mathrm{ml}$ of tap water. Dishes were placed in a germination cabinet (FLOHR Instruments GC 10/11; $20^{\circ} \mathrm{C}, 16$ h day, RH $98 \%$, 1000-1500 lux) and germination was monitored for 14 days. Seed was considered as germinated when the primary root and hypocotyl together exceeded four times the length of an individual seed

181 (International rules... 2005).

Prior to germination tests, seeds from each cone were x-rayed (Faxitron MX-20, IL, USA; Fuji medical x-ray film AD Mammography, exposure time $18 \mathrm{kV}, 10 \mathrm{~s})$. Based on the x-ray image, filled seeds were classified as follows; (1) seeds with visible differentiation between embryo, megagametophyte and seed coat (='normal seeds') and (2) seeds without visible 
187 1., cf. Simak 1980, Sahlen et al. 1995). In the following, these two types will be referred to

188 as category 1 and category 2 seeds. The former were found to be viable and capable of

189 germination. Category 2 'grey seeds', as based on our earlier experience do not germinate in

190 a germination test, and are somehow deteriorated. In esterase activity measurements (data

191 not shown) they have lower enzyme activity than viable, germinable seeds. Therefore,

192 statistical analysis of germination data was based only on the number of filled, viable

193 (category 1) seeds per cone. However, the proportion of these 'grey seeds' in each cone was

194 used as an independent variable when modelling the cone-wise germination response of 195 category 1 seeds.

\section{Weather data}

The weather data for the two growing seasons 2011 and 2012 were obtained using a set of climate data from the Finnish Meteorological Institute (Venäläinen et al. 2005). This data set consists of daily mean temperature and precipitation data interpolated onto a $10 * 10 \mathrm{~km}$ grid.

The growing season temperature sum, monthly mean temperature and precipitation during the seed maturation period (September - December) in the Suhola orchard, as well as their long time averages $(1981-2010)$ were calculated for the nearest grid, the center of which lies approximately $4 \mathrm{~km}$ north of the study site.

In order to describe the relationship between cone and seed water content, a non-linear

logistic function was used. As this model was only used for general description, a common

209 line was fitted to the data, ignoring the possible curvature differences according to clones and 
210 years. Further, we made the assumption that the continuous explanatory variable, cone water

211 content, was measured without error.

212 The cone and seed water content data were further analyzed with a linear mixed model to

213 estimate and partition the total random variability between and within individual clones,

214 grafts and cones. In this analysis, the collection date was taken as a fixed effect and clone,

215 graft and cone effects were considered random. The variance component model was:

$$
\mathrm{y}_{i j k l}=\mu+\mathrm{a}_{i}+\mathrm{b}_{i j}+\mathrm{c}_{i j k}+\mathrm{e}_{i j k l}
$$

where $\mathrm{y}_{i j k l}=$ observation on cone or seed sample from cone $l$ in graft $k$ in clone $j$ in collection

$219 i ; \mu$ is the intercept; $\mathrm{a}_{i}$ is the fixed collection date effect, $\mathrm{b}_{i j}$ is the random clone effect, $\mathrm{c}_{i j k}$ is

220 the random graft effect and $\mathrm{e}_{i j k l}$ is the random cone effect.

221 Statistical analysis of germination and seed deterioration data vs. cone water content and

222 freezing treatment could only be done with material from three collections (January and

223 March 2012, November 2012) as we had no values for individual cone water contents from

224 the first collection in Nov 2011.

225 The effect of cone water content on the presence of deteriorated, category 2 seeds (as

226 determined from the x-ray images) after cone freezing at $-30{ }^{\circ} \mathrm{C}$ was analyzed using a

227 generalized linear mixed model. This data was binary, as the response variable was

228 categorical with two classes: the presence of at least one deteriorated seed (yes/no) in a given

229 cone. Cone water content prior to freezing treatment (W), was used as a fixed term and

230 collection $x$ clone interaction as a random term. The random term imposes a correlation on

231 all observations from the same collection - clone combination.

232 The basic model was as follows: 
233

234

235

236

237

238

239

240

241

242

243

244

$$
\operatorname{logit}(\mathrm{p})=\mathrm{b}_{0}+\mathrm{b}_{1} \mathrm{~W}+\mathrm{u}_{\text {collection } x \text { clone }}
$$

where logit $(p)=$ the probability that at least one seed per cone is deteriorated. For binary data models in general the residuals provide no information about the adequacy of the fitted model (Collet 2003) and thus, we used ROC-curve analysis (Eng, 2014) as a checking diagnostic for this model.

The germination data was grouped binary, where the proportion of germinated seeds (out of the number of category 1 seeds per each cone) after 14 days of incubation was the response variable. Fixed terms in the model were: Cone freezing treatment $(\mathrm{F})$, cone water content prior to freezing treatment (W), and the proportion of category 2 seeds $(\mathrm{P})$ found in each individual cone (on x-ray image) after cone freezing. As with the seed deterioration model, we used collection $x$ clone interaction as a random term in order to take account of correlation among observations from the same collection and clone.

The basic form of the model was:

(3) $\quad \operatorname{logit}(\mathrm{p})=\mathrm{b}_{0}+\mathrm{b}_{1} \mathrm{~F}+\mathrm{b}_{2} \mathrm{~W}+\mathrm{b}_{3} \mathrm{P}+\mathrm{u}_{\text {collection } \mathrm{x} \text { clone }}$

where logit $(p)=$ germination percent of category 1 seeds after 14 days incubation.

Overall fit of the Model 3 was examined by looking at graphical summaries of the standardized residuals vs. fitted values and covariates. Individual model terms were assessed by comparing the log-likelihood statistics of two nested, candidate models and Wald significance tests for parameter coefficients. Fixed model terms were considered statistically significant at $\mathrm{p} \leq 0.05$. For all analyses, logistic regression procedures of Genstat 17 (VSN International...2014) were used. 


\section{RESULTS}

258 For each collection, seed and cone water content were closely correlated (Fig. 2.). The

259 general relationship could be described with a generalized logistic regression:

260 Seed water content, $\%=\mathrm{A}+\mathrm{C} /\left(1+\exp \left(-\mathrm{B}^{*}(\right.\right.$ Cone water content, $\left.\left.\%-\mathrm{M})\right)\right)$

261 with the following parameters (SE's in brackets):

$262 \quad \mathrm{~A}=11.156(0.552)$

$263 \quad \mathrm{~B}=0.225(0.0213)$

$264 \quad \mathrm{C}=21.86(1.08)$

$265 \mathrm{M}=31.715(0.378)$.

266 The regression accounted for $95.6 \%$ of the variance of the data; estimated standard error of 267 observations was $1.37 \%$.

268 On average, cones had $5-10 \%$ higher water content than the seeds inside them. Clonal, 269 seasonal and annual variation in both seed and cone water content was evident. In general, 270 the two consecutive crops were different: in November 2011, average water content of the 271 cones was $27.7 \%$ and $17.0 \%$ in seeds. The following year's crop had much higher average 272 values: $40.7 \%$ in cones and $29.8 \%$ in seeds, respectively (Table 1.).

273 In autumn 2011, clone E1881 had the highest cone water content (29.2\% fwt basis), whereas 274 next year, clone K393 had the highest values (46.9\%). Winter desiccation of cones and seeds 275 was obvious: during the period from November 2011 to March 2012 cones and seeds lost 276 approximately $7 \%$ and $4 \%$ of their fresh weight, respectively. Further studies by the authors 
277 indicate (data not shown) that during the winter 2013 - 2014 the cones and seeds dried down

278 to approximately 12 and $8 \%$ water content (fresh weight basis) respectively, before seed 279 dispersal.

280

281

Weather conditions

282 In both seasons, temperature climate during late stages of maturation in September-

283 November was milder than the long - term average, but the growing season 2011 as a whole

284 was considerably warmer with final temperature sum $\left(+5{ }^{\circ} \mathrm{C}\right.$ threshold $)$ reaching 1546.8

285 degree days. In 2012 the temperature sum was close to the average value on the study area.

286 In both years, cone collections were started approximately two weeks after the accumulation

287 of the temperature sum ended, ie. daily mean temperatures were constantly below $+5{ }^{\circ} \mathrm{C}$. In

288 terms of precipitation, September was exceptional in both years as monthly rain fall was 99.6

$289 \mathrm{~mm}$ in 2011 and $111.6 \mathrm{~mm}$ in 2012. These values are approximately twice and three times

290 the long - term average value, respectively (Table 2.).

Seed viability and germination after cone freezing in vitro

293

294

295

296

297

298

The probability of category 2 seeds in cones (as determined from x-ray images) and germination of category 1 seeds depended on cone water content at the onset of freezing treatment. The higher the cone water content, the higher was the probability of having at least one of category 2 seeds in a cone (Figure 3.). For Model 2, cone water content (Wald statistics $28.44 / 1 \mathrm{df})$ was statistically significant ( $\mathrm{p}<0.001$, Table 4.). ROC-statistics for this model were 0.972 (SE 0.017) indicating good fit (cf. supplementary Figure 1.) 
299 For germination, the situation was similar: the higher the cone water content at the onset of

300 freezing, the lower was the germination of filled, category 1 seeds from that particular cone

301 after treatment. For germination model, cone water content interaction with freezing

302 treatment (Wald statistics $205.8 / 1 \mathrm{df}$ ) and the proportion of category 2 seeds per cone (15.2

$303 / 1 \mathrm{df}$ ) were statistically significant factors affecting germination (Figure 4., Table 5., $\mathrm{p}<0.001$

304 for both terms). For model 3, standardized residuals vs. fitted values did not indicate any

305 problems, so we considered model fit to be satisfactory (cf. supplementary Figure 2.).

DISCUSSION

309 Cone water content and specific gravity have been used as an index of seed ripening for 310 many Pinus species (see Edwards 1980 for a comprehensive review), but only a few studies

311 have reported data on seed water content inside maturing Scots pine cones (Messer 1958, 312 Matyas 1971, Nygren \& Pulkkinen 1994, Tillman-Sutela \& Kauppi 2014). The results of this 313 study suggest, that seed water content can be predicted with a reasonable accuracy from cone 314 water content measurements. On average, cones had $5-10 \%$-units higher water content 315 than the seeds inside them.

316 Annual and clonal differences in cone and seed water content were obvious. High cone water 317 content values found in November 2012 may have resulted from high precipitation in the 318 study area during the month of September that year, as it was nearly three times the annual 319 long - term average value (Table 2.). In the previous year, precipitation in September was 320 also high (approximately twice the annual average), but due to a high temperature sum during 321 that season, cones and seeds may have dried prematurely and were not, perhaps, affected by 322 the high precipitation period in September. 
323 In a three - year study, Nygren \& Pulkkinen (1994) found that at the late maturation phase at

324 the end of October, Scots pine seed water content was approximately $20 \%$-units lower in a

325 warm growing season (1035 degree days, $+5{ }^{\circ} \mathrm{C}$ threshold) than in a cool season ( 869 degree

326 days). Tillman-Sutela \& Kauppi (2014) found that during two consecutive seasons in 1996

327 and 1997 Scots pine seed water content at the beginning of October was approximately $5-9$

$328 \%$-units lower in a warm growing season than in a cool season. The result was consistent

329 over three different geographical regions in Finland. The results of this study may indicate

330 that in a given clone, the rate of maturation drying is not the same every year. This was also

331 found by Remröd \&Alfjorden (1972) for a Scots pine seed orchard: 'early clones' in a given

332 year could be 'the late ones' in the next year. As suggested by Bonner (1991) orchard

333 managers should be familiar with the sequence and approximate dates of ripening of all their

334 clones. Due to limited number of clones in our study, our result needs to be confirmed with

335 more data so that the whole range of seed maturation within an orchard in different years

336 could be covered.

337 As revealed by variance component analyses, for each collection, the largest variation in both

338 seed and cone water content was at the cone level (Table 3.). This result has implications

339 when sampling cones for monitoring water content in the field, stressing the importance of

340 taking samples throughout different parts of the crown in each clone or tree. The estimated

341 zero variance component at the graft level is logical as grafts from the same clone are

342 genetically identical and thus, do not account for any of the random variation. The small part

343 of the variation explained by clonal level may be merely due to the fact that the number of

344 clones in our study was very limited. Thus, further research is needed to confirm these

345 results.

346 
347 Most studies on freezing tolerance of conifer seeds have been done in relation to the 348 germination process or seed storage conditions (von Schönborn 1964, Cremer \& Mucha 349 1985, Coursolle et al. 1998, Hawkins et al. 2003) but much less information is available on 350 their freezing tolerance while still intact in cones. Simak (1972), when studying the influence 351 of low temperatures (approximately $-3{ }^{\circ} \mathrm{C}, 2-3 \mathrm{~h}$.) on embryogenesis of Scots pine in vivo, 352 found that even in anatomically fully developed seeds, germination declined $15 \%$-units after treatment. Further, he observed differences in response between cones of a single tree as well as visual damage between individual seeds in a single cone. Our results indicate similar variation because after freezing treatment, an individual cone could include filled seeds of two categories: germinating, category 1 seeds, and presumably deteriorated, non-germinating 'grey seeds'(category 2). This classification is speculative, however, as we have only indirect and subjective evidence of seed deterioration, based on interpretation of $\mathrm{x}$-ray image data.

Whether freezing seeds in intact cones or after extraction, all studies indicate decreasing freezing tolerance of conifer seeds during the transition from a dry to imbibed condition. In general, our results are in agreement with those on freezing extracted Scots pine seeds in imbibed condition. According to Model 4 critical cone water content for $50 \%$ germination after freezing at $-30{ }^{\circ} \mathrm{C}$ was approximately $31.3 \%$ (fwt basis). This corresponds to approximately $21.6 \%$ water content in seeds.

A study by von Schönborn (1964) found that Scots pine seeds at 30\% water content (fresh weight basis) could withstand freezing to $-10{ }^{\circ} \mathrm{C}$, whereas at $10 \%$ water content they could survive at $-40{ }^{\circ} \mathrm{C}$. Hawkins et al. (2003) found that after freezing of imbibed seeds of lodgepole pine (with water contents varying from $25-45 \%$ ) to $-25{ }^{\circ} \mathrm{C}$, their survival ranged from 0 to $11 \%$. Pamuk et al. (2003) consider $15-20 \%$ water content to be the critical value 
372 for Scots pine seed freezing damage. This value is in agreement with that found in this study

373 but however, freezing duration in their experiment was much longer ( 2 and 5 days) than in

374 ours. Our results are also in line with the results from noble fir (Abies procera Rehd.) cone

375 and seed freezing tests (Tanaka 1980). Using his model, estimated germination of noble fir

376 seeds after cone freezing to $-30{ }^{\circ} \mathrm{C}$ at $35 \%$ cone water content is $7.9 \%$ and according to

377 Model 4 in our study it is $4.7 \%$ for Scots pine.

379 Tanaka (1980) observed that, with noble fir, the lethal temperatures were slightly lower in

380 cone freezing tests than in the seed-freezing tests and attributed this difference to the

381 insulating effect of cones scales when cones are frozen. Insulating effect is also important in

382 another aspect: Keefe and Moore (1982) could demonstrate that in Scots pine seeds, the three

383 - layer seed coat acts as nucleation barrier and retards ice growth towards inner seed

384 structures, the megagametophyte and the embryo. Therefore, surface dry although fully

385 imbibed (53.9\% water content dry weight basis) Scots pine seeds could stand sub-zero

386 temperatures better than those embedded in a moist substrate. damage than that observed in this study (Tanaka 1980).

In our study, germination of normal seeds (category 1, seeds without visible symptoms of damage in an x-ray image) was consistently lower if they came from the cones that had 
approximately $6.5 \%$ decrease in the odds of germination of other, healthy looking seeds in

398 that particular cone, also. We conclude that presence of 'grey seeds' in a cone indicates

possible damage to other seeds in that cone which, however, cannot be detected in

radiography. However, evidence of seed deterioration in our study is only indirect and has to

be interpreted with caution. Kardell $(1974,1976)$ hypothesized that, besides damage (as

determined with tetrazolium test) during overwintering, negative temperatures may induce dormancy in part of the Scots pine seeds, and that this dormancy could be broken by chilling.

Our results cannot confirm this hypothesis, as chilling treatment of filled, but nongerminating seeds was not included in our study.

\section{Conclusions}

The timing of cone collections according to seed maturation is one of the key questions in the management of Scots pine seed orchards. Much of the earlier work has been concentrated on monitoring anatomical seed development and especially embryo size, when predicting the quality of the seed crop. The results obtained in this study stress the importance of maturation drying in order for seeds to attain hardiness and remain viable throughout the winter months. It is suggested that monitoring cone water content should become a routine analysis in seed orchards and used as an indicator of both seed ripening and the development of Scots pine seed frost tolerance.

Our results also have implications for storing cones during the post-harvest period. In practical seed procurement, harvested cones are often stored outdoors for long periods. In these conditions, cones are subjected to freezing temperatures in late fall and early winter.

420 Emphasis should be put on protecting the cones from rain and allowing them to dry, exposed to free movement of air, in an interim storage shed or similar. 
423 Our results may have implications with respect to effects of climatic warming on

424 reproductive success of Scots pine. One of the most important ways by which northern

425 forests will respond to predicted climate change is through variations in seed maturation

426 (Meunier et al. 2007). Generally, growing season temperature conditions at the northern

427 latitudinal and upper altitudinal limits of Scots pine in Fennoscandia, are frequently too low

428 to permit normal seed development. At the polar timber line in northern Finland the

429 probability of achieving a mature, germinating Scots pine seed crop is very low,

430 approximately $0.02-0.03$ (Henttonen et al.1986). According to Almqvist et al. (1998) 975

431 degree days $\left(+5{ }^{\circ} \mathrm{C}\right.$ threshold, accumulated heat sum from start of the growing season until

432 August 31) are needed for 95\% germination of Scots pine seed. Current scenarios (Jylhä et

433 al. 2009) predict a significantly warmer future climate in Finland. This could mean improved

434 climatic conditions for Scots pine seed development and maturation in general. However, the

435 projected increase in precipitation - especially during the winter months and in northern

436 Finland - could disturb the maturation drying of seeds and their natural hardening in late fall

437 prior to severe winter conditions.

438

439 Acknowledgements

440 We thank Sirpa Kolehmainen and Mervi Ahonpää for their assistance in gathering the study

441 material and one anonymous reviewer for constructive suggestions and improvements in the

442 earlier version of the manuscript. 


\section{REFERENCES}

Almqvist, C., Bergsten, U., Bondesson, L. \& Eriksson, U. 1998. Predicting germination capacity of Pinus sylvestris and Picea abies seeds using temperature data from weather stations. Can. J. For. Res. 28:1530-1535.

Bonner, F.T. 1991. Seed Management. In Forest Regeneration Manual. Edited by M.L. Duryea and P.M. Dougherty. Kluwer Academic Publishers, pp. 51-73.

Collet, D. 2003. Modelling binary data. Second edition. Chapman \& Hall/CRC. 387 p.

Coursolle, C., Bigras, F.J. \& Margolis, H.A. 1998. Frost tolerance and hardening capacity during the germination and early developmental stages of four white spruce (Picea glauca) provenances. Can. J. Bot. 76:122-129.

Cremer, K.W. \& Mucha, S.B. 1985. Effects of freezing temperatures on mortality of air-dry, imbibed and germinating seeds of Eucalyptus and Radiata pine. Aust. For. Res. 15:243-251.

Edwards, D.G.W. 1980. Maturity and quality of tree seeds - a state-of-the-art review. Seed Sci. Technol. 8:625-657.

Eng J. 2014. ROC analysis: web-based calculator for ROC curves. Baltimore: John Hopkins University [updated 2014 March 19; cited 14.12.2014]. Available from:

http://www.jrocfit.org.

Håkansson, A. 1956. Seed development of Picea abies and Pinus silvestris. Medd. Statens Skogsforskningsinst. 46(2):1-23.

Hawkins, B.J., Guest, H.J. \& Kolotelo, D. 2003. Freezing tolerance of conifer seeds and germinants. Tree Physiology 23:1237-1246. 
Henttonen, H., Kanninen, M., Nygren, M. \& Ojansuu, R. 1986. The maturation of Pinus sylvestris seeds in relation to temperature climate in northern Finland. Scand. J. For. Res. $1: 243-249$.

International rules for seed testing. 2005. International seed testing association. Edition $2 / 2005$.

Jylhä, K., Ruosteenoja, K., Räisänen, J., Venäläinen, A., Ruokolainen, L., Saku, S. ja Seitola, T. 2009. Arvioita Suomen muuttuvasta ilmastosta sopeutumistutkimuksia varten, ACCLIMhankkeen raportti 2009. Extended abstract: The changing climate in Finland: estimates for adaptation studies. ACCLIM project report 2009. Finnish Meteorological Institute Reports 2009:4.

Kardell, L., 1974. Stratifieringsförsök med norrländsk tallfrö (Pinus silvestris L.). Summary: Stratification of Scots pine seeds (Pinus silvestris L.). Royal College of Forestry. Department of Silviculture. Research Notes 5:1-60.

Kardell, L. 1976. Frysförsök med norrländsk tallkott (Pinus silvestris L.). Summary: Freezing tests with cones of Scots pine (Pinus silvestris L.). Royal College of Forestry. Department of Silviculture. Research Notes 9:1-35.

Kardell, L., Nyman, B. \& Bobeck, S., 1973. Ripening process in relation to temperature and sugar content in seeds of Scots pine (Pinus silvestris L.). Studia Forestalia Suecica, (107):121.

Keefe, P.D. \& Moore, K.G. 1982. Frost damage during stratification: Mechanism and protection in Pinus sylvestris seeds. Seed Sci. \& Technol. 10:485-494. 
Kermode, A.R., Bewley, J.D., Dasgupta, J. \& Misra, S. 1986. The transition from seed development to germination: A key role for desiccation? HortScience 21(5):1113-1118.

Matyas, Cs. 1973. Handling of autumn harvested cones in Scotch pine seed orchards. In Proceedings of IUFRO International symposium on seed processing, Bergen, Norway. Vol. I(13):1-13.

Meunier, C., Sirois, L. \& Begin, Y. 2007. Climate and Picea mariana seed maturation relationships: a multi-scale perspective. Ecological Monographs 77(3):361-376.

Messer, H.W. 1958. Das Fruchten der Waldbäume als Grundlage der Forstsamengewinnung. I. Koniferen. J.D.Sauerländer's Verlag, Frankfurt am Main.

Nygren, M. \& Pulkkinen, M. 1994. Seed mass growth in two Pinus sylvestris clones. Reports from the Foundation for forest tree breeding 9, $11 \mathrm{p}$.

Owens, J.N. \& Blake, M.D. 1985. Forest tree seed production. Petawawa National Forestry Institute. Canadian Forestry Service. Information Report PI-X-53.

Pamuk, G., Bergsten, U. \& Lingois, P. 2003. Freezing response in Scots pine seeds as assessed by DSC and germination test. Seed Technology 25(2):92-103.

Remröd, J. \& Alfjorden, G. 1972. Tidpunkt för kottinsamling i tallfröplantager. Summary: The time for cone collection in seed orchards of Scots pine (Pinus silvestris L.). Föreningen skogsträdsförädling, Årsbok 1972, 139 - 162.

Sahlen, K. \& Abbing, K. 1995. Effects of artificial environmental conditions on anatomical and physiological ripening of Pinus sylvestris L. seeds. New Forests 9:205-224.

Sahlen, K., Bergsten, U. \& Wiklund, K. 1995. Determination of viable and dead Scots pine seeds of different anatomical maturity after freezing using IDX method. Seed Sci. \& Technol. $23: 405-414$. 
Sarvas, R. 1962. Investigations on the flowering and seed crop of Pinus silvestris.

Communicationes Instituti Forestalis Fenniae 53.4.

Schönborn, A. von. 1964. Die Aufbewarung des Saatgutes der Waldbäume. Bayerischer Landwirtschftsverlag GmbH, München.

Simak, M. 1972. Låga temperaturers inverkan på embryoutvecklingen hos tallfrö (Pinus silvestris L.). Summary: The influence of low temperature on embryogenesis in Scots pine. Skoghögskolan, Inst. för skogsföryngring, Rapporter Nr 36:1-14.

Simak, M. 1980. X-radiography in research and testing of forest tree seeds. Swedish Univ. of Agricultural Sciences, Dept. of Silviculture. Report 3:1-34.

Tanaka, Y. 1980. Effect of freezing temperatures on noble fir seed during cone storage. In Proceedings of IUFRO International symposium on forest tree seed storage. Chalk River, Ont. 23-27 September 1980. Compiled and edited by B.S.P.Wand and J.A. Pitel, Petawawa National Forestry Institute, Chalk River, Ont. pp. 68-74.

Tillman-Sutela, E. \& Kauppi, A. 2014. Maturity of surface structures in northern Pinus sylvestris L. seeds: A key to improved prediction of germination potential. Flora 209:45-53. Venäläinen, A., Tuomenvirta, H., Pirinen, P. \& Drebs, A. 2005. A basic Finnish climate data set 1961-2000 - description and illustrations. Finnish Meteorological Institute, Reports No. 2005:5

VSN International (2014). GenStat for Windows 17th Edition. VSN International, Hemel Hempstead, UK. Web page: GenStat.co.uk. 


\section{TABLES}

Table 1 . Cone and seed water content ( $\%$, fresh weight basis; mean \pm SE) by clone in different collections. For every collection, each clone is represented by 9 -15 cones from three randomly selected grafts; from each cone a bulk sample of $15-20$ seeds was analyzed.

\begin{tabular}{|c|c|c|c|c|c|c|c|c|}
\hline \multirow[b]{3}{*}{ Crop 2011} & \multicolumn{8}{|l|}{ Clone } \\
\hline & \multicolumn{2}{|l|}{$\underline{\mathrm{K} 393}$} & \multicolumn{2}{|l|}{ K689 } & \multicolumn{2}{|l|}{ E1181 } & \multicolumn{2}{|l|}{ K942 } \\
\hline & Cone & Seed & Cone & Seed & Cone & Seed & Cone & Seed \\
\hline Nov 2011 & $27.7(0.4)$ & $17.4(0.2)$ & $26.3(0.4)$ & $16.7(0.4)$ & $29.2(0.4)$ & $16.7(0.3)$ & .. & .. \\
\hline Jan 2012 & $27.3(0.6)$ & $16.9(0.2)$ & $26.4(0.6)$ & $17.1(0.2)$ & $28.4(0.6)$ & $17.0(0.2)$ & .. & .. \\
\hline March 2012 & $21.5(0.5)$ & $13.6(0.3)$ & $19.9(0.5)$ & $12.5(0.3)$ & $21.0(0.5)$ & $13.2(0.3)$ & .. & .. \\
\hline \multicolumn{9}{|l|}{ Crop 2012} \\
\hline Nov 2012 & $46.9(2.1)$ & $35.1(1.8)$ & $37.6(1.1)$ & 27.3 & $43.3(0.4)$ & $30.1(0.3)$ & $35.1(0.8)$ & $26.5(0.9)$ \\
\hline
\end{tabular}


Table 2. Annual temperature sum $\left(+5^{\circ} \mathrm{C}\right.$ threshold), monthly precipitation and mean temperature in the study area during the seed maturation period.

\begin{tabular}{lccccccc} 
Year & \multicolumn{1}{c}{ Temperature sum } & \multicolumn{2}{c}{ Precipitation, $\mathrm{mm}$} & \multicolumn{3}{c}{ Mean temperature, ${ }^{\circ} \mathrm{C}$} \\
& & Sep & Oct & Nov & Sep & Oct & Nov \\
2011 & 1546 & 99.6 & 48.9 & 30.4 & 11.1 & 5.6 & 1.9 \\
2012 & 1302 & 111.6 & 60.5 & 40.6 & 10.4 & 4.1 & 1.1 \\
Average (1981-2010) & 1258 & 48.2 & 54.7 & 47.6 & 9.0 & 3.8 & -2.0 \\
\hline
\end{tabular}


Table 3. Components of variance for cone and seed water content (fresh weight basis) based on mixed linear Model 1.

\begin{tabular}{llll} 
Term & Variance estimate & SE & Proportion, \% \\
\hline Cone water content & & & \\
Clone level & 2.202 & 1.589 & 24.3 \\
Graft level & -0.139 & 0.125 & 0.0 \\
Cone level & 6.864 & 0.672 & 75.7 \\
Seed water content & & & \\
Clone level & 1.184 & 0.941 & 19.4 \\
Graft level & -0.061 & 0.108 & 0.0 \\
Cone level & 4.934 & 0.484 & 80.6 \\
& & & \\
\hline
\end{tabular}


Table 4. Parameter estimates (with SE) of the Model 2.

\begin{tabular}{lcccc} 
Fixed parameters & estimate & SE & t-value & appr. p-value \\
\hline Constant & -19.73 & 4.04 & -4.884 & $<.001$ \\
Cone water content & 0.641 & 0.12 & 5.342 & $<.001$ \\
& & & & \\
Random parameters & & & & \\
Heterogeneity factor & -0.887 & 0.14 & -6.336 & $<.001$ \\
Collection x Clone & -2.39 & 1.04 & -2.291 & 0.112 \\
\hline
\end{tabular}


Table 5. Parameter estimates (with SE) of the Model 3.

Fixed parameters

Constant

Cone water content

Freezing treatment ${ }^{a}$

Cone water x Freezing treatment ${ }^{a}$

Proportion of deteriorated seeds/cone

Random parameters

Collection x Clone

${ }^{a}$ as compared with control at $+5^{\circ} \mathrm{C}$ estimate... SE......t-value.......appr. p-value

$\begin{array}{llll}3.578 & 0.550 & 6.505 & <.001 \\ 0.0021 & 0.0102 & 0.2059 & 0.413 \\ 12.86 & 1.090 & 11.798 & <.001 \\ -0.5559 & 0.0388 & 14.327 & <.001 \\ -0.0669 & 0.0171 & 3.912 & <.001\end{array}$

$\begin{array}{lll}-2.252 & 0.520 \quad 4.331\end{array}$

$<.001$ 


\section{FIGURE CAPTIONS}

Figure 1. Example of an x-ray image of a fully developed Scots pine seed (category 1, middle) and two seeds without visible differentiation of embryo and megagametophyte and showing even optical density throughout the image (='grey seeds', category 2).

Figure 2. Scatterplot showing the general relationship between water content (fwt basis) of Scots pine cones and the seeds inside them in different collections and the predicted value according to generalized logistic function.

Figure 3. Probability of presence of at least one category 2 seed ('grey seeds', as determined from $\mathrm{x}$-ray image) in an individual cone after $2 \mathrm{~h}$ cone freezing treatment at $-30{ }^{\circ} \mathrm{C}$, as a function of cone water content (fresh weight basis) at the onset of freezing (Model 2 ).

Figure 4. Model 3 predictions of germination of category 1 Scots pine seeds from individual cones after $2 \mathrm{~h}$ cone freezing treatment at $-30{ }^{\circ} \mathrm{C}$ as a function of cone water content (fresh weight basis) at the onset of freezing. Open circles: Control seeds after storage of cones at $+5^{\circ} \mathrm{C}$; triangles: seeds from cones that had no deteriorated (category 2 ) seeds after freezing; squares: seeds from cones that had $5 \%$ deteriorated (category 2 ) seeds after freezing. The standard errors are approximate as the model is not linear. 
1 Figure 1.

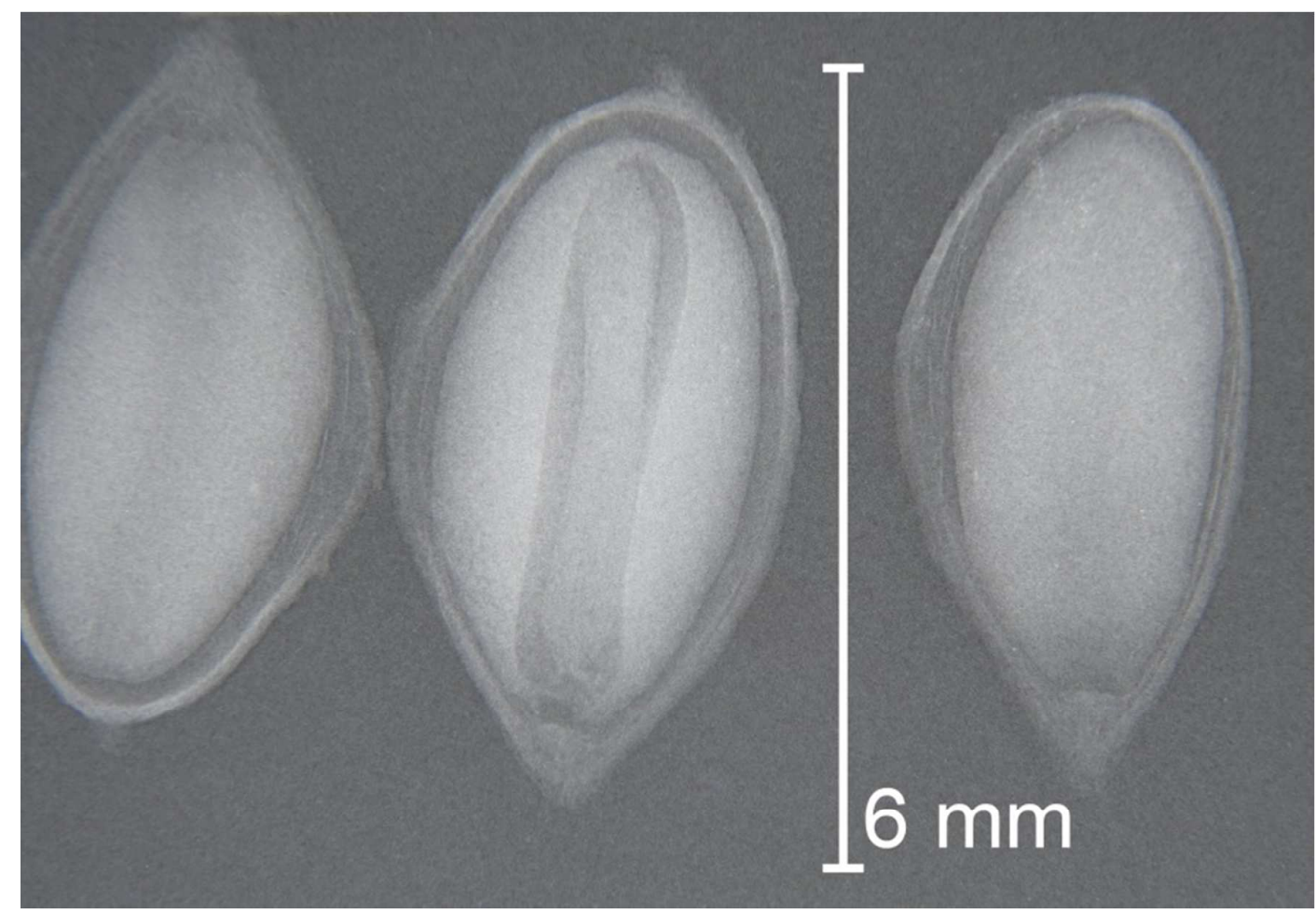


15 Figure 2.

16

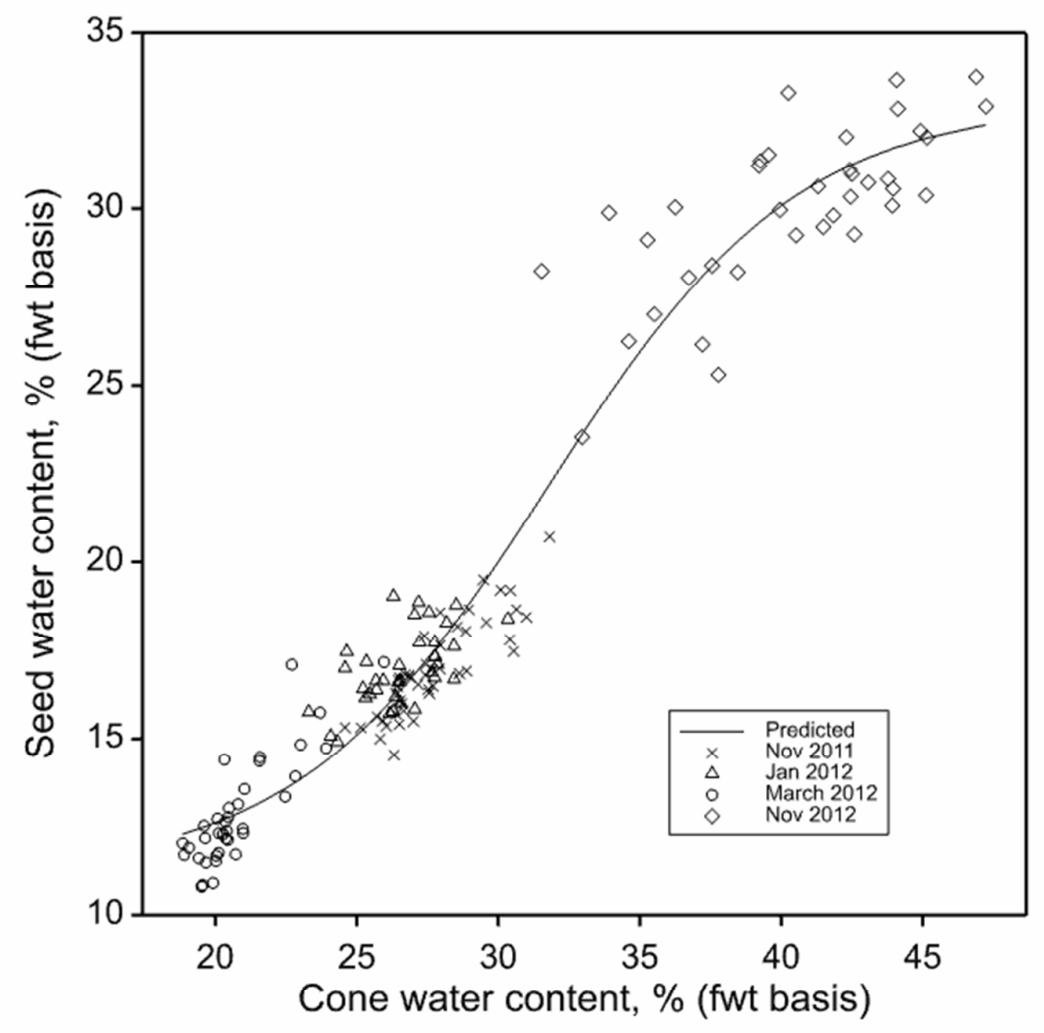


26 Figure 3.

27

28

29

30

31

32

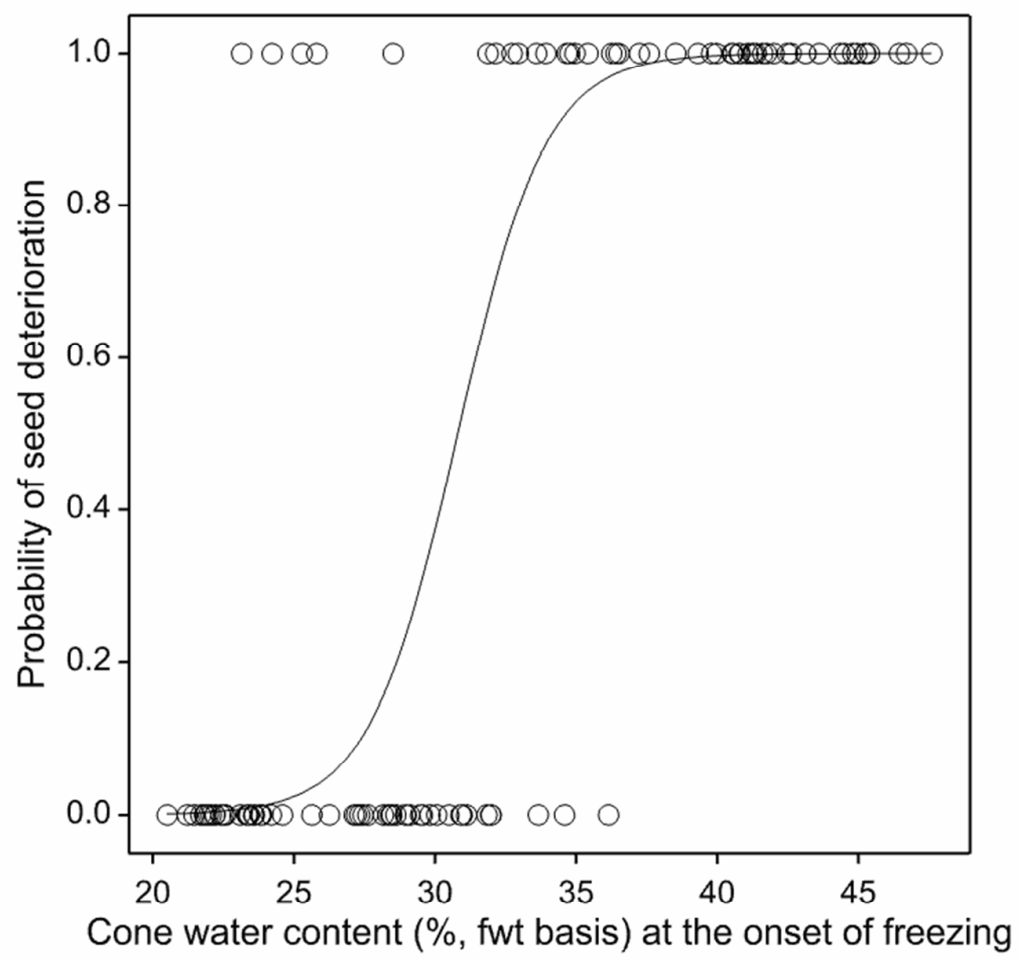

33

34 
$36 \quad$ Figure 4.

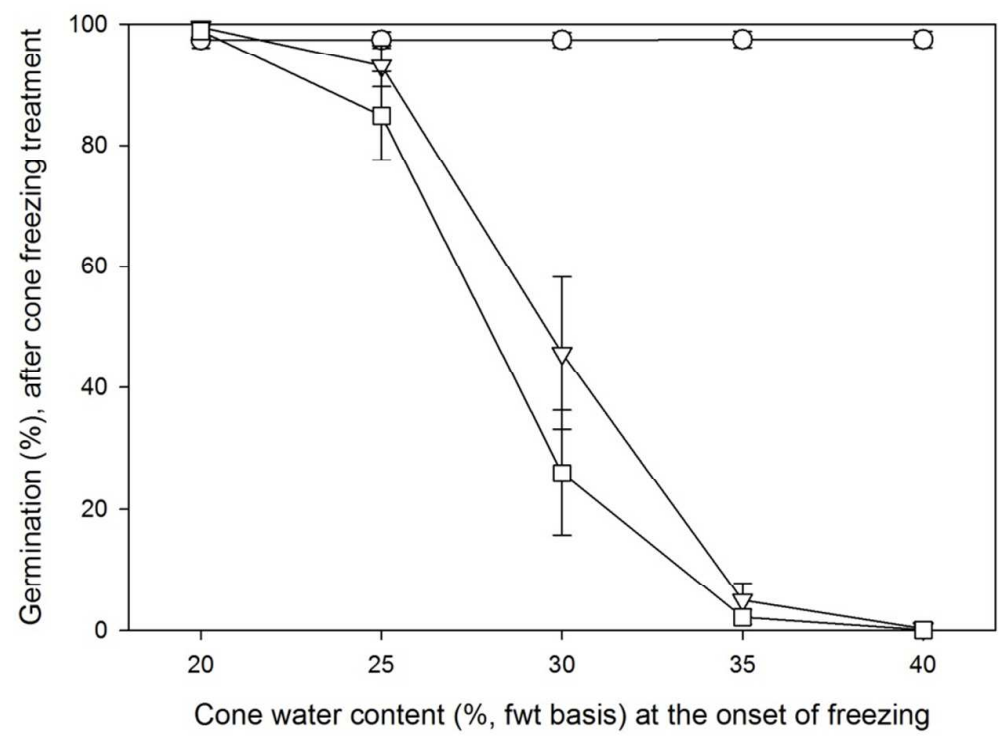


SUPPLEMENTARY MATERIAL

roc; binary model, 17.1.2016; area: 0.972 (SE 0.017)

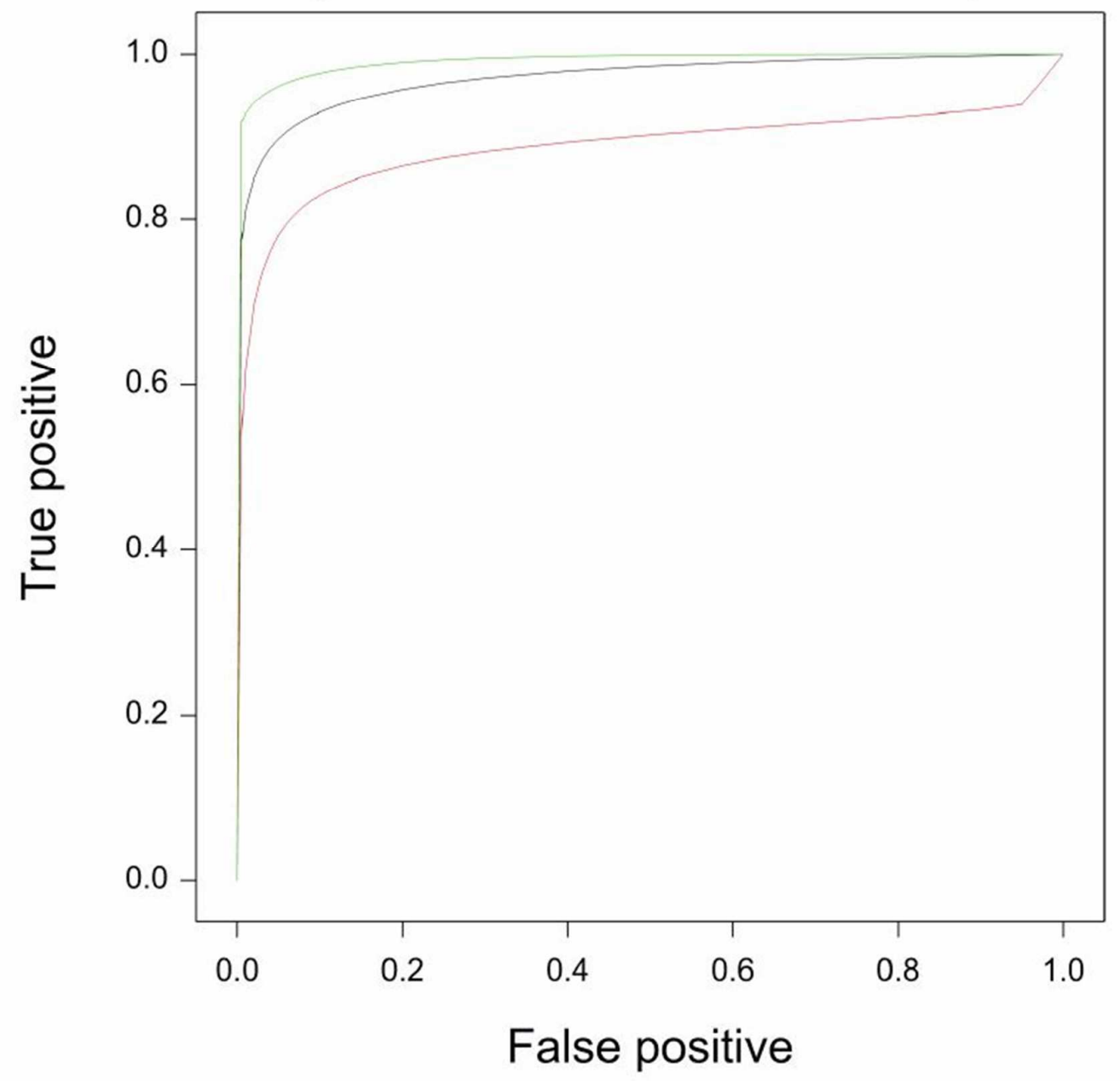

Supplementary Figure 1. ROC-curve ( $\pm 95 \%$ confidence limits) for Model 2. 


\section{iti14 vs. freeze ${ }^{*}$ cone water + grey $\%+u$}
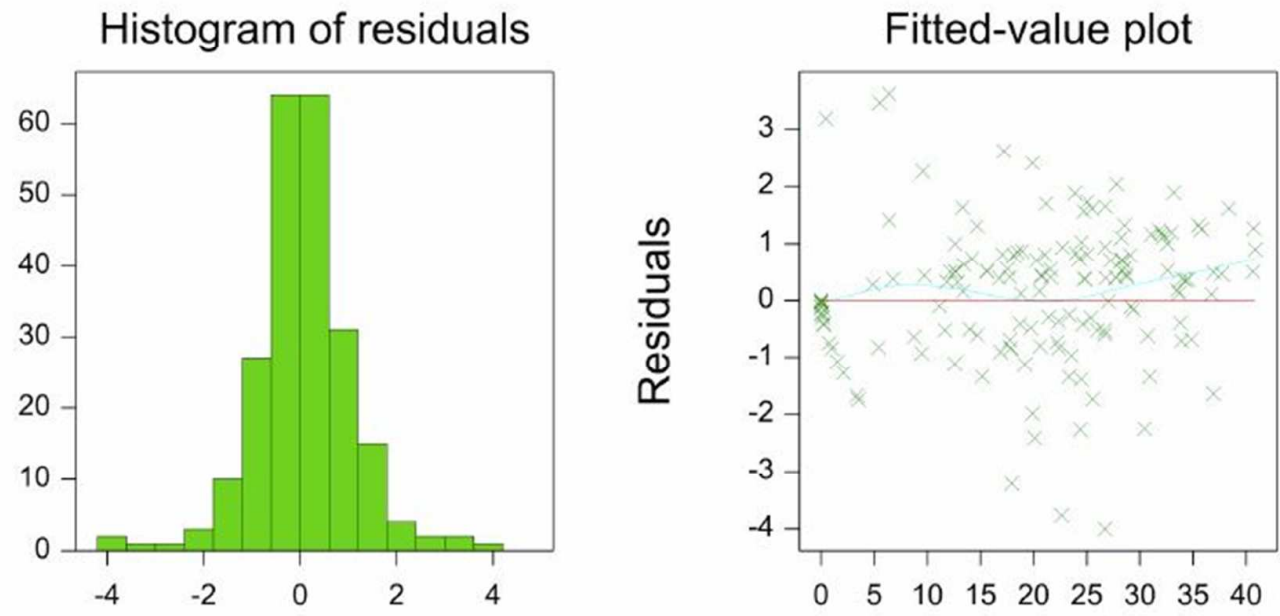

Fitted values

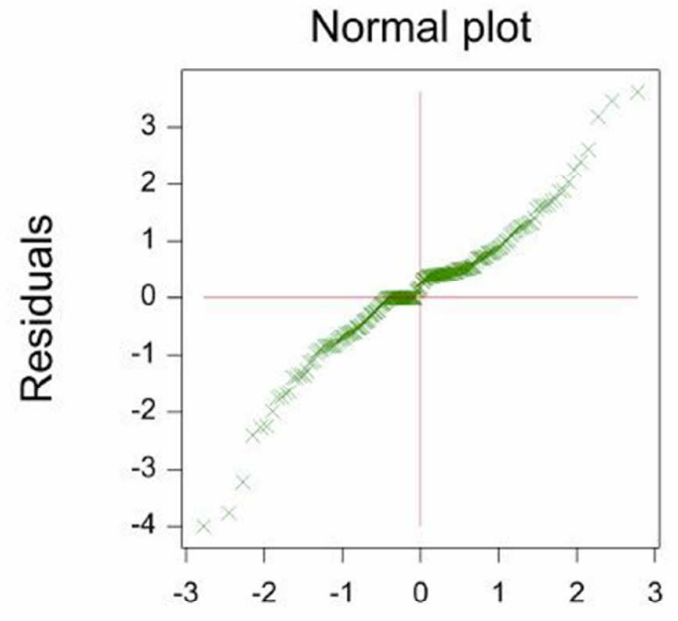

Expected Normal quantiles

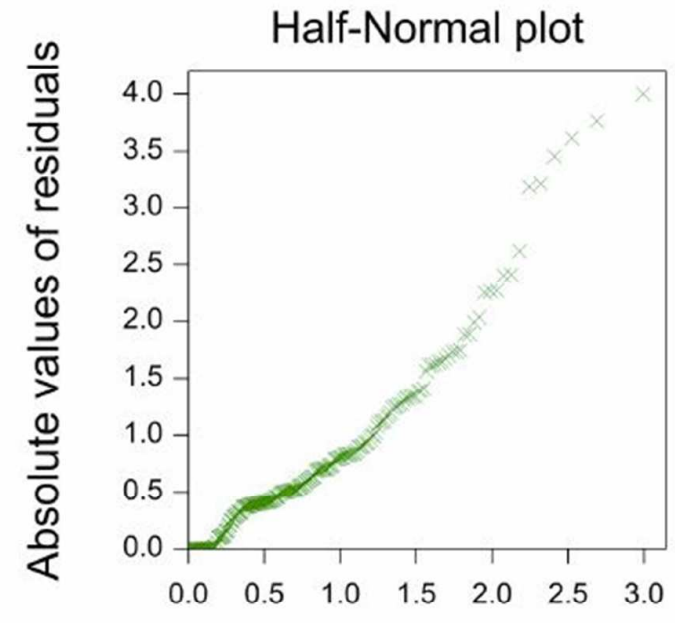

Expected Normal quantiles

Supplementary Figure 2. Residual diagnostics of the Model 3. 